\section{Response to: 'Clinical evidence guidelines in systemic lupus erythematosus: revaluation' by Scheinberg}

We want to thank Dr Morton Scheinberg for his interest ${ }^{1}$ in our recent lupus guidelines communication. ${ }^{2}$ In his letter, he points out several concerns regarding belimumab which we had recommended at the same therapeutic level as other immunosuppressants for joint and skin manifestations. Few clarifications are needed.

The development of our guidelines followed a rigorous methodology in which the evidence on effect estimates should come, when available, from randomised controlled trials (RCTs). We did not identify any clinical trial comparing belimumab against other immunosuppressants. Therefore, in considering this comparison, the development group had to rely on indirect evidence (the difference in belimumab effect against placebo and other immunosuppressants against placebo) or high risk of bias evidence (from observational studies). In this context, the panel agreed that the certainty that belimumab was better (or worse) than other immunosuppressants was low/very low and therefore decided not to recommend one over the others.

Dr Scheinberg emphasised that in constructing the recommendation we missed relevant information; nevertheless, he did not provide any additional data that could justify this affirmation (RCT about the effects of belimumab in comparison with other immunosuppressants), instead he referenced a non-comparative observational study, ${ }^{3}$ an RCT that was included in our review and considered in constructing the recommendations ${ }^{4}$ (the reference provided was from a longer follow-up timeframe that was published after the systematic search of our guideline was finished whose results confirmed earlier findings), and a cost-effectiveness analysis that did not model belimumab against other immunosuppressants ${ }^{5}$ (only modelled belimumab as add-on therapy) and was based on the information of the BLISS trials, ${ }^{46}$ also included in our review. We acknowledge that not providing a recommendation (between different immunosuppressants) could not be the best of the guidance as, in practice, guideline users need to decide which one to prescribe; nevertheless, we agreed that in the absence of a head-to-head RCT, a conservative approach (providing the evidence and panel judgements without a recommendation) was the best way to proceed.

We are glad that Dr Scheinberg is concerned about the side effects of glucocorticoids as we do. For that reason, we have emphasised this as an overarching principle.

Finally, the letter mentions difficulties on expert consensus methodology. ${ }^{7}$ We agree and have intensively lived that experience in the past. That is why, for these guidelines, we had decided to incorporate a transparent guideline development methodology in which the recommendations were intended to be based on the best available evidence such as the Grading of Recommendations Assessment, Development and Evaluation system, just as described in the editorial.

We very much appreciate Dr Scheinberg's encouraging and insightful comments. We eagerly await new strong clinical evidence of current and new therapeutic options for our patients with lupus.

\footnotetext{
Bernardo A Pons-Estel, ${ }^{1}$ Eloisa Bonfa, ${ }^{2}$ Enrique R Soriano, ${ }^{3,4}$ Mario Humberto Cardiel, ${ }^{5}$ Ariel Izcovich, ${ }^{6}$ Gloria Vázquez, ${ }^{7}$ Graciela S Alarcón ${ }^{8,9}$
}

'Departamento de Medicina Interna, Grupo Oroño-Centro Regional de Enfermedades Autoinmunes y Reumáticas (GO-CREAR), Rosario, Argentina

${ }^{2}$ Division of Rheumatology - Hospital das Clinicas HCFMUSP, Facultade de Medicina, Universidade de São Paulo, São Paulo, Brazil

${ }^{3}$ Sección de Reumatología, Hospital Italiano de Buenos Aires, Buenos Aires, Argentina ${ }^{4}$ Fundación Dr. Pedro M. Catoggio para el progreso de la Reumatología, Buenos Aires, Argentina

${ }^{5}$ Centro de Investigación Clínica de Morelia, Morelia, México

${ }^{6}$ Hospital Alemán de Buenos Aires, Servicio de Clínica Médica, Buenos Aires, Argentina

${ }^{7}$ Universidad de Antioquia, Hospital Universitario, Fundación San Vicente, Medellín, Colombia

${ }^{8}$ Division of Clinical Immunology and Rheumatology, Department of Medicine, School of Medicine, The University of Alabama at Birmingham, Birmingham, Alabama, United States

${ }^{9}$ Department of Medicine, Universidad Peruana Cayetano Heredia, Lima, Peru

Correspondence to Dr Mario Humberto Cardiel, Centro de Investigación Clínica de Morelia, Morelia 58070, México; mhcardie|@hotmail.com

Handling editor Josef S Smolen

Contributors All authors listed in this manuscript have participated in planning, drafting, reviewing, final approval and are accountable for all aspects of the manuscript.

Funding The authors have not declared a specific grant for this research from any funding agency in the public, commercial or not-for-profit sectors.

Competing interests BAP-E has been a speaker for GlaxoSmithKline. ERS has received research grants and has been a lecturer for Roche. MHC has received research grants from Roche and is an advisor for Eli Lilly.

Patient consent Not required.

Provenance and peer review Commissioned; internally peer reviewed.

(c) Author(s) (or their employer(s)) 2019. No commercial re-use. See rights and permissions. Published by BMJ.

\section{Check for updates}

To cite Pons-Estel BA, Bonfa E, Soriano ER, et al. Ann Rheum Dis 2019;78:e120.

Received 5 October 2018

Accepted 6 October 2018

Published Online First 23 October 2018

\section{S Linked}

- http://dx.doi.org/10.1136/annrheumdis-2018-214357

Ann Rheum Dis 2019;78:e120. doi:10.1136/annrheumdis-2018-214385

\section{REFERENCES}

1 Scheinberg M. Clinical evidence guidelines in systemic lupus erythematosus: revaluation. Ann Rheum Dis 2018. doi: 10.1136/annrheumdis-2018-214357. [Epub ahead of print: 25 Sep 2018].

2 Pons-Estel BA, Bonfa E, Soriano ER, et al. First Latin American clinical practice guidelines for the treatment of systemic lupus erythematosus: Latin American Group for the Study of Lupus (GLADEL, Grupo Latino Americano de Estudio del Lupus)-PanAmerican League of Associations of Rheumatology (PANLAR). Ann Rheum Dis 2018. doi: 10.1136/annrheumdis-2018-213512. [Epub ahead of print 25 Jul 2018].

3 Fanouriakis A, Adamichou C, Koutsoviti S, et al. Low disease activity-irrespective of serologic status at baseline-associated with reduction of corticosteroid dose and number of flares in patients with systemic lupus erythematosus treated with belimumab: a real-life observational study. Semin Arthritis Rheum 2018. doi: 10.1016/j. semarthrit.2018.02. [Epub ahead of print $23 \mathrm{Feb} 2018$ ].

4 Furie RA, Wallace DJ, Aranow C, et al. Long-term safety and efficacy of belimumab in patients with systemic lupus erythematosus: a continuation of a seventy-six-week phase iii parent study in the United States. Arthritis Rheumatol 2018:70:868-77.

5 Díaz-Cerezo S, García-Aparicio ÁM, Parrondo J, et al. [Cost-effectiveness analysis of Belimumab in patients with systemic lupus erythematosus in Spain]. Farm Hosp 2015:39:161-7.

6 Navarra SV, Guzman RM, Gallacher AE, et al. Belimumab, a BLyS-specific inhibitor, reduced disease activity, flares and prednisone use in patients with active SLE: efficacy and safety results from the phase 3 BLISS-52 study. Lancet 2011;377:721-31.

7 Barosi G, Gale RP. Is there expert consensus on expert consensus? Bone Marrow Transplant 2018;53:1055-60. 